\title{
Promoting Reflexivity in Masters Research: Reflections on a 20-year Teaching Partnership Between Maynooth University and the Irish Defence Forces.
}

\section{Angela McGinn}

\begin{abstract}
This paper serves as an introduction to this second edition of the Journal of Military History and Defence Studies. It explains the origin and nature of the educational partnership that exists between the Irish Defence Forces and Maynooth University. In particular, it focuses on the MA in Leadership, Management and Defence Studies (LMDS), a masters level postgraduate qualification embedded into the Joint Command and Staff Course. It discusses the philosophy that underpins the programme, emphasising the ways in which it seeks to enhance the students' capacity for reflexivity and criticality, before introducing each contribution in this edition, all of which are based on research undertaken as part of the MA in LMDS.
\end{abstract}

"A critical curriculum does not supply answers. It supplies questions" ${ }^{1}$

The MA in Leadership, Management and Defence Studies (MA LMDS) provides University accredited military education for midranking Officers in the Irish Defence Forces. This programme, which commenced in 2002, was initially developed in partnership with the Maynooth University Department of Adult Education and the Irish Defence Forces. It is now jointly delivered by staff from the Centre for Military History and Strategic Studies, Department of History, and the Military College within the Defence Forces Training Centre, the Curragh, Co Kildare.

In 2001, staff from the Department of Adult Education in Maynooth, notably Professor Anne Ryan and Dr Tony Walsh, established a significant educational partnership with the Defence Forces which aimed to:

Build on the existing Command and Staff course in such a way that it would provide a learning experience that was appropriate in the rapidly changing world in which today's military are called to operate; 
Deliver the MA programme as effectively as possible, taking account of the professional experiences of this particular student body and the resource limitations of the organisations involved;

Utilise the partnership and the MA programme to contribute to the overall organisational development of the Defence Forces. ${ }^{2}$

20 years on, our primary goals remain the same; the MA is embedded within the Joint Command and Staff Course (formerly the Senior Command and Staff course) and encompasses all elements of military teaching, dedicated academic modules and a research thesis.

Military education is different in that it presents specific teaching and learning challenges for both instructors and learners. Typically, military students experience far higher levels of direct instruction over a compressed time period, than their civilian counterparts on a conventional Masters programme. A recent piece by David Morgan-Owen highlights how, when facing the challenges of military education and its competing agendas:

... voices in uniform play a vital role, particularly when it comes to defining the specific skills necessary for staff and command appointments. Yet civilians also play a crucial part, offering professional educational expertise, alternative viewpoints, and high-quality teaching and research ${ }^{3}$.

Our partnership approach addresses this key issue and has evolved to incorporate best practice in teaching and learning from Maynooth University and the Military College. We foreground the development of officer students' critical thinking skills and reflexivity, prioritising awareness of "the personal, social and cultural context in which we live and work and to understand how these impact on the ways we interpret the world." 4 We seek to create in our students, an awareness of the 'grand discourses' or 'meta narratives' in which we are all positioned. These discourses, encompassing nationality, gender, culture and organisation specific ways of thinking and behaving are often taken for granted and unchallenged. "Discourses privilege certain understandings, behaviours and ways of being as incontestable, valid and of value." 5 Discourses 'rule in' values and behaviours that are seen as acceptable and legitimate within cultures, societies and organisations and also 'rule out' or restrict others $^{6}$.

In the early days of the partnership Ryan acknowledges how both the members of the university team and the staff and students of the military college were "embedded in their respective organisations."7 Over the intervening years, through the education of over 200 military officers, and the evolving understandings of both parties, our pedagogical approach has been refined. On one hand, we recognise the need to provide "clarity and precision" in our expectations, but on the other we have incorporated a reflexive approach to teaching and tailored our approach to engage students in concepts that they may find "unfamiliar and at times unsettling." ${ }^{8}$ This is neither a finite nor a linear process ${ }^{9}$, it continues to change as new people join the teams and existing staff become familiar with the systems and cultures of both institutions. In addition, the turnover of military instructors is typically high, which can result in issues of continuity for both the students and 
University staff ${ }^{10}$. Often our expectations and rationale need to be re-examined and re explained, with the concurrent advantage of avoiding stagnation in our understandings and approaches.

Integral to the MA programme, is the production of a research thesis. This provides a site for students to engage in critical reflexivity and through this process develop new knowledge of relevance to both the Irish Defence Forces and the wider military and academic communities. It is acknowledged ${ }^{11}$ that building students' capacity to successfully undertake research "requires a combination of theoretical understanding, procedural knowledge and mastery of a range of practical skills."12 Therefore, students on the MA participate in a research methodology module which promotes active engagement with a range of philosophical perspectives, paradigms and methodological tools that underpin research in the humanities and social sciences. However, we recognise that "the task of teaching research methods [...] is not the transmission of a body of knowledge, or the drilling of students in the use of techniques, but rather a matter of helping them to build up relevant knowledge and capabilities, and to develop the necessary intellectual virtues."13 Many military students enter the MA with professional or academic qualifications in science or engineering and struggle with connecting qualitative and quantitative methods to "a set of philosophical assumptions about the nature of the social world."14

As educators we are acutely aware of how reflexivity impacts on "the kind of knowledge produced and how that knowledge is generated." ${ }^{15}$ Pedagogically, our overall goal on the MA, is to increase students' capacity for reflexivity and criticality. In a research context this is concerned with turning "the researcher lens back onto oneself to recognise and take responsibility for one's own situatedness within the research and the effect that it may have on the setting and people being studied, questions being asked, data being collected and its interpretation." ${ }^{16}$ Students are facilitated in developing skills which allow them to "interrogate experiences, seeking to examine not only their origins, but also those blind spots, illusions and selfdeceptions that crucially and legitimately make them up." ${ }^{17}$ We are particularly concerned with raising students' awareness of how their own positionality influences their approach. Berger articulates this as follows: "the researcher must remain constantly alert to avoid projecting his or her own experience and using it as the lens to view and understand participants' experience" ${ }^{18}$. This is vital when working with military students who are often unaware of their own interpretive lenses. When encouraging students to move "beyond the surface, [they] often notice that no knowledge is value free." 19

In teaching, we actively avoid techniques of instruction focused on "mastering a limited range of technical skills largely divorced from the context in which those skills may be applied." 20 Instead we incorporate techniques such as "experience sampling'21 -dipping into learners' existing experiences to aid methodological understanding into our pedagogical practice. The effective use of questions, allowing students to relate material to their own stories and experience and sharing these experiences with classmates and instructors leads to effective learning and engagement with methodologies. ${ }^{22}$ Illustrating ideas and arguments through metaphors and vignettes ${ }^{23}$ assists in framing lecture material in a way that students can relate to in the context of their own lives. 
Students apply their learning to a real-world defence related issue or problem; they develop appropriate research standpoints and design a methodology that specifically addresses their own research needs. This learning by doing "can help convey the work of qualitative research, the methodological decisions required to do such research well, and some of its potential rewards." ${ }^{24}$ We also assign mentors, in the form of military and academic supervisors. These supervisors are allocated to work in a partnership arrangement, with each other and with the student, thereby bringing a range of professional skills to the supervision relationship. This also has the advantage of simultaneously developing military instructors' educational and supervisory skill sets. Supervision meetings are held as group and individual sessions affording students the opportunity to receive feedback from their peers as well as their instructors. Students are actively encouraged to journal their experiences on the course and the thesis process in a learning portfolio. Pillow and Mayo emphasise how this process of writing makes "visible the questions, complexities and processes of doing research." 25

In conclusion, we aim to actively connect learners to research, provide opportunities for active engagement in research and promote reflexivity and criticality. Ultimately, the final test of our approach is measured in the quality of student engagement, learning and research output. We are optimistic that the body of research that has been amassed over the last 20 years had contributed in a significant way to the evolution of the Defence Forces as an organisation. Knowledge has emerged that covers a diverse range of personal, group, organisational and transnational topics, and has been utilised to inform new doctrine, policies and procedures. Previous theses are available for consultation by students and the wider Defence Forces membership.

This issue of the Journal contains a cross section of research submitted by the students of the MA LMDS. The articles present work that has been revised and edited to match the journal format.

Mark Lennon's research employs a mixed methods approach to explore the factors that determine an individual's decision to enlist in the Irish Defence Forces. An understanding of these factors is critical in terms of recruitment and retention at a time where the Defence Forces face particular challenges in terms of high turnover rates and a difficult recruitment environment. Mark identifies specific motivations involved in the decision to enlist, and then widens his research to explore important influencers in this process. One of his key conclusions is the development of an overarching recruitment policy which recognises the importance of understanding recruit motivation.

The Irish Defence Forces have a long and significant peacekeeping tradition. Rory Esler's research focuses on the area of Civil Military Co-operation (CIMIC) in the United Nations Interim Force in Lebanon (UNIFIL). He critiques the methods through which the Defence Forces select and train personnel for UN CIMIC tasks drawing on International military best practice as a basis for comparison. He concludes with a number of key recommendations to develop pre-deployment training with an emphasis on 'soft skills' and cultural awareness. 
Padraic Kennedy explores the importance of documenting oral history. He identifies a gap in Defence Forces doctrine relating to the establishment of a formal methodology for the collection of narratives, acknowledged as important for leadership development and the enhancement of collective organisational memory. He proposes that widening the scope of the Oral History project within the military will allow for the compilation of more nuanced and contextual accounts which will provide a vital resource for Defence Forces personnel and academic researchers.

Orla Jennings draws on the unique experiences of women soldiers who are also mothers. Through semi structured qualitative interviews she sensitively explores how motherhood results in identity tensions and promotes a reevaluation of priorities particularly in relation to career progression. Whilst women soldiers demonstrate considerable commitment to the Defence Forces, the organisations failure to recognise specific obstacles faced by soldiers who are also mothers has implications for retention, motivation and organisational capability.

René Ochs is one of the officers from the German Bundeswehr who have participated in the MA over the past 20 years. His research explores differences in understanding relating to mission command amongst NATO members and how such differences can give rise to difficulties in relation to leadership, communication and intent. He explores the possible routes to resolve these issues and create conditions necessary for the successful application of mission command. 
${ }^{1}$ Carole Edelsky, Making Justice our Project: Teachers Working Toward Critical Whole Language Practice. (Urbana, IL: National Council of Teachers of English, 1999), p.31.

${ }^{2}$ Anne Ryan, 'A learning partnership: NUIM and the Irish Defence Forces', in T. Walsh (ed) Building a Better Future: Contributions by the Irish Defence Forces, (Maynooth: MACE Press, 2011), p. 55.

${ }^{3}$ David Morgan-Owen, Professional Education and Military Learning in the 21st Century [Online]. Available from:

https://warontherocks.com/2018/07/approaching-a-fork-in-the-road-professionaleducation-and-military-learning/ [Accessed 3 November 2020].

${ }^{4}$ Kim Etherington, Becoming a Reflexive Researcher, (London: Jessica Kingsley, 2004), p. 19

${ }^{5}$ Ryan, A learning partnership, p. 57.

${ }^{6}$ Stuart Hall, 'Who needs identity?' In P. du Gay, J. Evans \& P. Redman (eds.) Identity: A Reader. (London: Sage, 2000), pp. 15-30.

${ }^{7}$ Ryan, A learning partnership, p. 58.

8 Ibid, p. 59.

${ }^{9}$ Ibid

${ }^{10}$ Richard H. Thain, Ambrose McDonough \& Alan D. Priestley, 'The development and implementation of a teaching and learning strategyat a modern military academy', Journal of Further and Higher Education, Vol. 32, Issue 4, 2008, pp. 297308.

${ }^{11}$ Daniel Kilburn, Melanie Nind, \& Rose Wiles, 'Learning as researchers and teachers: The development of a pedagogical culture for social science research methods?' British Journal of Educational Studies, Vol. 62, 2014, pp. 191-207.

12 Kilburn et al, 'Learning as researchers' p. 191.

${ }^{13}$ Martyn Hammersley, 'Is it possible to teach social research methods well today?' Discussion paper presented at HEA Social Sciences Teaching and Learning Summit: Teaching Research Methods, (University of Warwick, 21-22 June 2012), p.2.

${ }^{14}$ Sharlene Hesse-Biber, S. 'The problems and prospects in the teaching of mixed methods research', International Journal of Social Research Methodology, Vol. 18, Issue 5, 2015, pp. 463-477; Hesse-Biber, p. 465.

${ }^{15}$ David Deggs, \& Frank Hernandez, 'Enhancing the value of qualitative field notes through purposeful reflection', The Qualitative Report, Vol. 23, Issue 10, 2018, pp. 2552-2560; Deggs \& Hernandez, p. 2553.

${ }^{16}$ Roni Berger, 'Now I see it, now I don't: Researcher's position and reflexivity in qualitative research', Qualitative Research, Vol. 15, Issue 2, 2015, pp. 219-234; Berger, p. 220. 
${ }^{17}$ Yiannis Gabriel, 'Narratives, stories, and texts', In C. H. D. Grant, Hardy, C. Oswick, \& L. Putnam (eds.), Sage Handbook of Organizational Discourse, (London: Sage, 2004), p. 74.

${ }^{18}$ Berger, 'Now I see it', p. 330

${ }^{19}$ Chandra Bowden, (2016). 'Teaching and learning the unteachable', In M. KoroLjungberg, Reconceptualizing Qualitative Research, (Thousand Oaks, CA: Sage, 2016), p. 146.

20 John Maclnnes, 'Quantitative methods teaching in UK Higher Education: The state of the field and how it might be improved', Paper presented at HEA Social Sciences Teaching and Learning Summit: Teaching Research Methods, (University of Warwick, 21-22 June 2012), p. 2.

${ }^{21}$ Shandra Hesse-Biber, cited in Lewthwaite \& Nind, p. 422. Lewthwaite, S. \& Melanie Nind, 'Teaching research methods in the social sciences: Expert perspectives on pedagogy and practice', British Journal of Educational Studies, Vol. 64, Issue 4, 2016, pp. 413-430.

22 Bowden, 'Teaching and learning'

${ }^{23}$ James Carifio, \& Lisa Erikson, 'Towards a theory and view of teaching compressed and abbreviated research methodology and statistics courses', Journal of Social Sciences, Vol. 3 Issue 4, 2007, pp. 250-259.

${ }^{24}$ Dydia DeLyser, et al 'Teaching qualitative research: Experiential learning in groupbased interviews and coding assignments', Journal of Geography, Vol. 112, Issue 1, 2012, pp. 18-28; DeLyser et al, p. 18.

${ }^{25}$ Wanda S. Pillow, \& Cris Mayo, 'Toward understandings of feminist ethnography. In S. N. Hesse-Biber (ed.), Handbook of Feminist Research: Theory and Praxis, (Thousand Oaks, CA: Sage 2007), p. 163. 